J. Fixed Point Theory Appl. 10 (2011) 1 DOI 10.1007/s11784-011-0057-9

C Springer Basel AG 2011
Journal of Fixed Point Theory

and Applications

This Festschrift is dedicated to

\title{
Richard S. Palais
}

honouring over 50 years of his important and influential accomplishments in Global Analysis, Transformation Groups and Morse Theory.

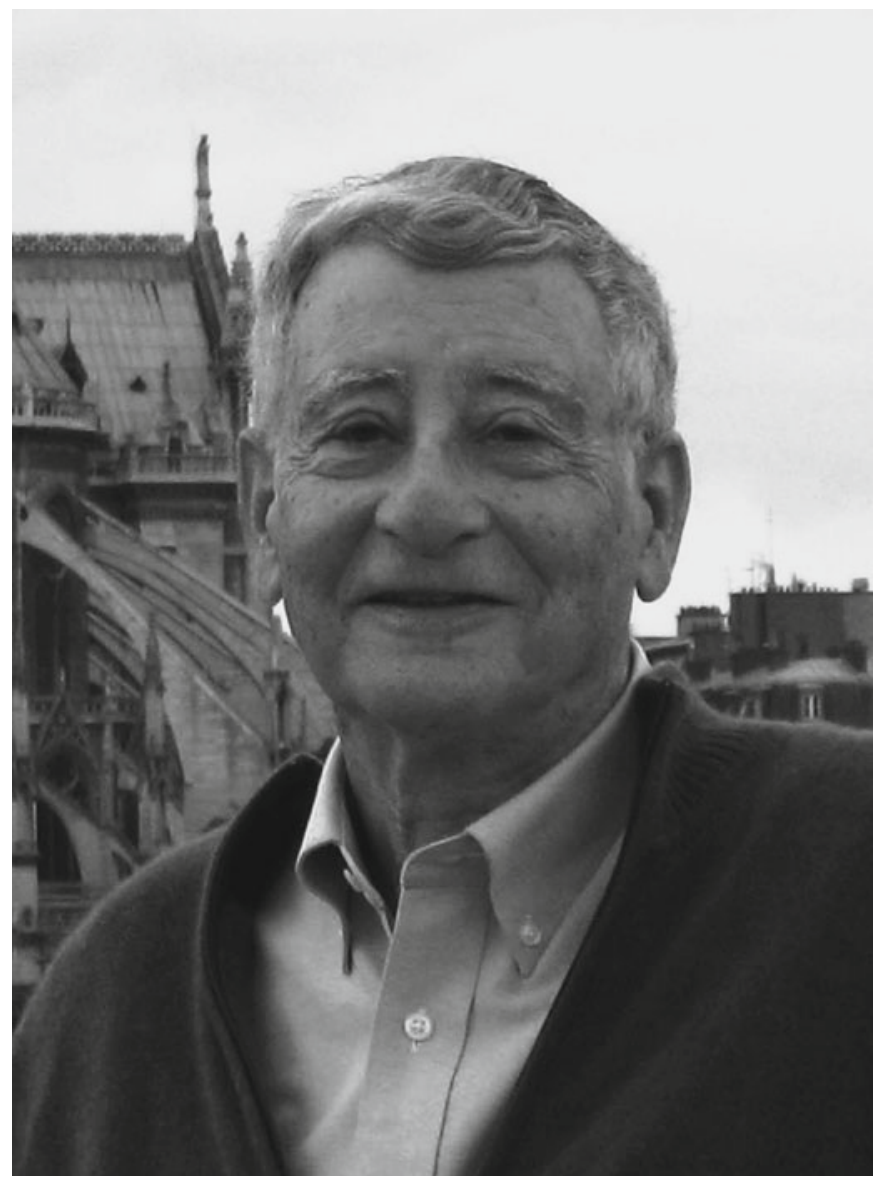

